\title{
Emotional Labour and Identity Work of Men in Caring Roles
}

\section{Dr Ruth Simpson}

\author{
Brunel Business School \\ ruth.simpson@brunel.ac.uk
}

This paper presents the findings of a research project on the implications of men's nontraditional career choices, specifically those that involve caring roles, for the performance of emotional labour and for gender identity. The research is based on 25 in-depth interviews with male nurses and primary school teachers in the UK. Results suggest firstly that men 'appropriate' caring as a valued resource which is separate from caring performed by women, secondly that a division of emotional labour emerges that is drawn on 'tradition' gender lines and thirdly that men adopt various strategies to help align their work and gender identity and to minimize tensions between the two. The dynamics of performing 'women's work' and of maintaining and reproducing masculinities within the non-traditional 'caring' work setting are discussed in the light of recent theorising around gender, emotions and organizations.

Key words: caring, masculinity, emotional labour

\section{INTRODUCTION}

This paper explores the gendered nature of emotional labour and how this informs and influences the identities of male carers. Emotional labour refers to the ways individuals change or manage emotions to make them appropriate with a role or an expected organizational goal (Hochschild, 1983; Sturdy, 1992). Men and women are increasingly moving into gender atypical areas and while there is extensive literature on women in male dominated occupations (e.g. Kanter, 1977; Simpson, 2004; 2005; Ely, 1994), there is little research on men who perform what could be seen as 'women's work'. This research needs priority given the widespread changes in the occupational structure in Western economies over the past decade including the feminization of local labour markets, the undervaluation of female dominated work and current labour shortages in many 'caring' roles. An understanding of the experiences of men in these roles can therefore go some way to challenge and breach sex stereotypic career boundaries. At the same time, while the gendered nature of emotional labour has been extensively acknowledged in much of the literature (with strong associations made between such roles and femininity), masculinity and emotional labour in the context of caring professions have been relatively neglected areas. Given the significance of organizations for definitions of masculinity and for characterizations of 'masculine' and 'feminine' work (Morgan, 1992), there are likely implications for masculine 
identities when men occupy 'feminine' roles that involve service and care. In this context, masculinity is 'on the line', highly visible and vulnerable to challenge (ibid). This paper accordingly explores emotional labour and identity work of men in two female dominated ‘caring' occupations: nursing and primary school teaching.

\section{PREVIOUS RESEARCH}

\section{A Typology of Emotional Labour}

The growth of services and the culture of the customer have led to a greater emphasis on emotional labour as a source of competitive advantage (Sturdy, 1998). Caring for others, the need for personal and interpersonal skills and the presentation of a 'happy face' have therefore become part of the production process and there is now a body of work exploring the emotional labour process and the costs or otherwise to the individual (e.g. Morris and Feldman, 1996; Wouters, 1989) Hochschild (1983), for example, has highlighted some of these costs as the emotional labourer complies with feeling rules prescribed by organizational norms and so becomes increasingly alienated from their work. This views feelings as market based commodities (Morris and Feldman, 1996) to be controlled and organizationally ascribed (Mumby and Putnam, 1992). Other work, however, adopts a more optimistic stance and points to some of the positive outcomes from emotional labour in the form of selfaffirmation and job satisfaction (Morris and Feldman, 1996; Wouters, 1989).

As Bolton (2003; 2005) points out, this conceptualisation of emotional labour is based on the view that feelings are commodities, organizationally ascribed and controlled for instrumental ends. This notion may therefore be inappropriate for the analysis of public sector caring roles i.e. where a service is provided that is not directly for profit and where individuals can exert an active and controlling force in relationships with customers, clients and managers. Definitions of emotional labour may therefore need to differentiate between emotion work as part of the capitalist labour process and emotion work due to professional norms of conduct where some autonomy may exist in terms of how that labour is carried out - as well as between care as a commodity in the service sector and care as part of a 'gift exchange'. As Bolton argues, it is difficult to see how nurses caring for the dying or teachers dealing with an upset child do emotional labour according to a single definition based on commercial gain.

Bolton accordingly has developed a typology of emotion work based on different feeling rules: pecuniary emotion work which conforms to the above definition in that it is based on organizationally prescribed feeling rules geared towards profit; prescriptive emotional labour which conforms to feeling rules dictated by professional norms of conduct; and presentational emotional labour which relies on social norms and feeling rules geared towards the 
maintenance and facilitation of the interaction order. The latter may include for example philanthropic emotion management whereby emotional labourers give a 'bit extra' by going beyond the call of duty in their caring role (supporting a stressed colleague, spending time with a distraught relative). Based on the above typology, this research has drawn on different feeling rules that shape how emotional labour is carried out in nursing and teaching (i.e. prescriptive and presentational) in order to explore the gendered nature of emotional labour and how men perform emotion work in these caring roles.

\section{GENDER AND EMOTIONAL LABOUR}

Emotional labour can be seen as gendered at several levels. Firstly, it is associated with the sexual division of labour whereby men have traditionally been located within the world of (rational) production while women have been assigned to caring and nurturance in the private sphere of the home (Taylor and Tyler, 2000; Sturdy, 2002). This sexual division of labour has therefore been based upon and has contributed to the split in society between personal feelings and economic production as well as to the divisions between the rational and the emotional and between the public and private. These divisions have profound gendered implications. In particular, the dominance of rationality in Western thought has been shown to be steeped in discourses and images of masculinity (Ross-Smith and Kornberger, 2004). Such dominance has been at the expense of emotion, which has been sidelined as 'irrational, private, inner sensations tied historically to women's dangerous desires and 'hysterical' bodies' (Sturdy, 2002). In a similar vein, the apparent location of emotions in the private domain (James, 1989) as well as assumptions around their 'natural' association with women, has led to their gendered connection with the domestic and with femininity. The division between the private domain of home and the public domain of workplace compounds the already low status of 'natural' unskilled women's work carried out under the auspices of the gender division of labour and perpetuates the emotional and rational divide of male and female. Emotional labour is therefore predictably a gendered phenomenon underwritten by the interplay of the gendered ambiguity of emotions themselves, the sexual division of labour and the division of the public and the private.

Much of the rationale of the above is predicated on a belief that emotions are the 'natural' domain of women. A second aspect of the gendered nature of emotional labour therefore concerns women's 'natural' capacities to deliver service (Taylor and Tyler, 2000; Guerrier and Adib, 2004) and so constructed (and hence concealed and devalued) as a 'natural' part of doing gender (Hall, 1993; Adkins, 2001). Gendered assumptions about the natural abilities of women consequently inform managerial attempts to prescribe emotional labour (Taylor and Tyler, 2000). As Taylor and Tyler point out in the context of the airline industry, women are expected to put up with more hassle from customers and are judged by 'hard' and 'soft' 
standards (i.e. getting a sale and interaction with customers) while men are only judged by the 'hard' standard of getting a sale. Emotional labour that involves caring for others is seen as suitable for women by virtue of their difference from men i.e. seen as 'common sense' ways of being a woman. Therefore management assumes that women workers in particular can accomplish the 'caring' part of the job involving interpersonal skills which they are supposed to possess by virtue of their sexual difference from men, capacities which are deemed to derive from women's 'Otherness'. So emotional labour is seen as women's work in that the majority of those employed are women and it is deemed to draw on abilities that women are supposed to possess by virtue of their sexual difference from some norm of masculinity.

A third orientation towards gender and emotions constructs emotional labour as a cultural performance (e.g. Butler, 1994; Sass, 2000). Cultural performances are episodes through which members construct organizational reality (Williams, 2003). As Butler (1994) argues, gender provides much of the meaning for these performances via repeated acts which conform to norms of what constitutes male and female. Therefore as Williams (2003) points out the cultural performance of emotional labour is a gendered performance and the emphasis is on doing or acting out gender according to norms and expectations which in turn help to construct and negotiate gender identities. For example, in the context of service, gender is constructed and acted out through the service encounter and through management prescriptions and constraints such as through the legitimation of the image of the deferential servant (Hall, 1993) and by enacting gendered scripts of good service. In this way, as Mulholland (2002) points out, the gender subtext or hegemonic gender regulation shape the articulation of emotional labour during the service interaction.

\section{CARING AND MASCULINITY}

While much of the above work draws parallels between emotional labour and femininity, where this has particular reference to service and caring roles, this paper explores the gendered nature of emotional labour as acted out in caring roles by drawing links between these roles and masculinity. Much of the literature on men in non-traditional occupations has focussed on aspirations and careers where it has been suggested that men are rewarded for their difference from women in terms of higher status and pay (Williams, 1993; Floge and Merril, 1986) and that they draw on assumptions of enhanced leadership and authority associated with a masculine identity to ascend the hierarchy more quickly than female counterparts (Bradley, 1993). The more limited work on masculinity and emotional labour (e.g. Hochschild,1983; Heikes, 1991; Williams, 1993) suggests that caring work such as teaching and nursing, which call for special abilities that only women are deemed to possess, can create problems for men as they negotiate a masculine identity. Men may call into 
question their competence and suitability if they assert a traditional masculinity and yet invite challenges to their sexuality and masculinity if they adopt a more feminine approach.

These challenges raise issues about how male workers reconcile the feminine nature of their work with the demands of a hegemonically masculine gender regime. As Lupton (2000) found, men working in female dominated occupations fear feminization and stigmatization. One response is to engage in compensatory gendered practices so as to minimize its nonmasculine associations and to restore a dominating position (Alvesson, 1998). This can be achieved by emphasizing the male and downplaying the female elements of the job (Williams, 1993). This can manifest itself in a preference for managerial and authority roles (Bradley, 1993) or for roles that require technical expertise and/or physical strength (Heikes, 1991; Simpson, 2004). Such strategies suggest a tension for men in non-traditional roles between the 'feminine' nature of the job and dominant discourses of masculinity. One outcome therefore may be attempts to align occupational and gender identities through a division of labour within the female role that is drawn along traditional gendered lines.

\section{AIMS AND METHOD}

The overall aim of the project is to explore the gendered nature of emotional labour and how this informs and influences the identities of male carers in two public sector service and caring occupations: nursing primary school teaching. In accordance with the three strands of literature on gender and emotions outlined above, and drawing on Bolton's typology as an organizing principle, it set out to examine the following interrelated areas:

- to explore the nature of any gendered division of emotional labour within nursing and primary school teaching.

- to explore perceptions of the match between personal capabilities and skill requirements or demands of the job.

- to explore potential mismatch between gender and occupational identity and how men manage any tension in this respect.

A total of 25 interviews were conducted. The fifteen nurses interviewed came from six different hospitals in the South-East of the UK. Five were involved with mental health, four in accident and emergency, one in palliative care and the remainder were in general nursing. The ten primary school teachers interviewed were employed in six different schools around London. Two were on the senior management team, one was nursery manager and seven were main scale class- room teachers.

Interviews were semi-structured and followed a set of themes as outlined in the research questions above. Interviews were tape-recorded, transcribed and analysed using framework 
analysis as outlined by Ritchie and Spencer (1996). This is a grounded approach in that theory emerges from data and in that it is heavily based in and driven by the original accounts and observations of people it is about. It involves a number of distinct though highly interconnected stages which do not necessarily follow a particular order, some of which have overlapping qualities with the grounded theory approach of Corbin and Strauss (1990). These processes involve sifting, charting and sorting material according to key issues and themes.

\section{RESULTS}

\section{The Gendered Division of Emotional Labour}

While emotional labour in the form of caring has been associated with femininity in that it draws on feminine attributes of nurturing and service to others, data suggests a gendered division of labour within the caring role. This division of labour can be seen to be drawn along traditional gender lines. Part of this division related to choice of specialism within the profession. For example, in nursing, five of the fifteen men interviewed had chosen to specialise in mental health which was seen as more demanding and 'masculine' with historical links with discipline, restraint and custodialism. Similarly, four men had chosen accident and emergency (described by one nurse as 'jumping on chests in casualty'), seen as more exciting and demanding than general nursing care. While there is less room for specialism within primary school teaching, most men were involved in sport and took a special interest in the sporting development of male pupils.

A gendered division of labour also emerged within the caring role itself in terms of the type of emotional labour undertaken. For example, in teaching men were called upon to take on the role of disciplinarian and authority figure - to adopt a father role - while in nursing men were often given more challenging and difficult tasks such as dealing with suicidal patients or breaking bad news to relatives.

They (the children) come to me on more disciplinary matters... So I get a lot of disciplinary things to deal with. So if there's a fight, if there's a disagreement they will come to me

Looking at people to whom I've broken bad news, they appreciate that it's a man who's breaking bad news...doctors are men and I know I'm not a doctor but I think people see a man breaking bad news as a positive, like it means more

In both occupations, prescriptive feeling rules (i.e. those relating to professional norms of conduct) dictated appropriate behaviour with children and female patients and imposed constraints on how emotional labour was performed. Teachers in particular had to keep a 
physical distance from children, a problem when circumstances demanded that they receive comfort and support.

If you've got a child who's really worried and upset instinct tells you to put your arm round them but you don't - you get somebody else in there to witness - a female teacher would not have the same stigma attached to it. It is restricting because you might want to break through to a child.....and you cannot do it any other way

Masculinity could thus be problematic and could restrict some aspects of caring. Men's bodies were often seen as 'out of place'. One nurse reported the remark of a female colleague during his midwifery training: 'we don't want nasty smelly men in here'. However, the value of masculinity in terms of the respect commanded within the caring role was a common theme. As one teacher commented 'with all children being a bloke gets you a lot more kudos', while a nurse pointed out that 'if the charge nurse is a male he gains more respect than the ward sister, where discipline, structure, routine has to be respected and abided with'.

Several men claimed a specialist knowledge which was separate from the lesser knowledge of general nursing (largely performed by women) and which allowed entry to the professional (and rational) world of doctors on the ward. This entry, often based on appeals to fratriarchal ties, was highly valued and a further source of differentiation from women.

'I do have a close relationship with the (male) doctors - I find that I can be pally with them and sit down and chat with them and we can talk about men things'

This entry however was not fully secure and male nurses told stories of conflict where organizationally prescribed norms of deference were overturned.

I do know that the junior doctors have been afraid of me because I've told them off, if I don't think they're doing something safely I'm quite happy to say let me do it, or I'll show you'

I was at a meeting yesterday and there was three consultants were just chit chatting away while I was trying to discuss something and I asked them if they could keep quiet and they just carried on chatting so I said if you don't **** shut up I'm going to walk out of here...

These stories and the activities on which they are based serve to reposition the nurse away from a subordinate role and towards a status that has equal (or superior) value to that of the doctor. The licence to be openly critical of male doctors did not extend to female nurses who 
were seen to be too deferential and unassertive. As a result they were not always taken seriously by male medical staff:

I get on very well with the consultant...he would respect me for what I've done and the majority of the time he would back me up - whereas if a female colleague approached him and said I am very concerned about one of the patients, he has many a time said to female colleagues you are projecting your own anxiety'

Overall, evidence suggests the existence of a gendered division of labour with men choosing more 'masculine' specialisms within the occupation. At the same time, men performed an authoritarian 'father' role and were assigned more difficult tasks as well as, in some cases, more challenging emotion work. Prescriptive feeling rules dictated how men performed emotional labour in that a greater physical distance was expected between the emotion worker and the child or female patient. Some unity with the work performed by doctors and separation from the work performed by female nurses was claimed though some tension and conflict around the potential for inclusion or exclusion (from the male medical profession) was evident in this respect.

\section{Gender, Personal Capabilities and Skill Requirements of Emotion Work.}

Most nurses and teachers perceived themselves to have relevant 'caring' skills and capabilities, though these were often seen to be different from the 'natural' capabilities held by women. Women were seen by many to be more nurturing and to have greater compassion though differences from men were highlighted.

'There's a nurturing there though slightly more father-like - its nurturing in a different way and maybe less informal' (teacher)

'I think men can bring a certain a different sort of compassion to the job that's more equal like between mates...' (nurse).

The nurturing capabilities of men were therefore often mentioned as 'different' from women. At the same time, they were seen as 'different' from men.

I think in a way I'm not your average male because I'm more caring towards children...I just have a soft spot for children and so I do have a lot more time for them and I can have a little bit more emotional contact with them'

I'm a very caring sort of person and I'll talk to them (the children) which sometimes the Dads don't have time or the inclination to do 
This caring side was often celebrated and valued for itself:

I'm a very caring sort of person...I feel quite happy being seen in a more motherly role. I've got no problems with my feminine side at all - I'm quite proud of it (teacher)

I think that's partly why I'm a nurse because I have that particular deep level of nourishing that makes me able to do that (help a dying patient) rather than sitting like a truck driver by the side of the bed...I went and I held her hand and we talked about her job as a seamstress and I was quite happy to sit there doing all the things I had to do while talking about embroidery and crotchet work because I think it's easy to talk to old ladies and put their minds at rest'

While the caring performed by women is often devalued as a 'natural' part of femininity (Taylor and Tyler, 2000), emotional labour performed by men can accordingly be celebrated as an asset, divorced from nature and hence acquiring a special status and value. This special status may arise because of claimed differences from women (more rational, more equal) as well as claimed differences from the rest of men. This difference may help promote perceptions of a 'gift' exchange as incorporated into Bolton's (2005) philanthropic emotion management. This is the ability to go the extra mile in the service encounter despite other demands on the server's time. Therefore, rather than 'sitting like a truck driver by the side of the bed' (a masculine configuration) the nurse quoted above felt able to offer extra support to his patient that went beyond the call of duty. Similarly, another nurse felt that, unlike his female counterparts who were less likely to make the extra effort for a patient, he was willing and able to mobilise resources to give that additional care:

I think men tend to be more understanding - not so short tempered, we maybe don't rush around - I've worked with someone (female nurse) who was I've got to do this, I've got to do that, always here, there and everywhere and the patient becomes a very poor third and I think that men tend to be more placid and listen to the patient - and if what the patient wants does not fit what the ward can do then we'll try and get something changed so that can happen, rather than just say oh we can't do that because....

Perceptions of the match between personal capabilities and the demands of the job therefore revealed claims of difference from women as well as from the majority of men. This differentiation served to highlight the special nature of the skills required and, as we have seen, may lay the foundations for perceptions of a gift exchange. 


\section{Occupational and Gender Identity}

Discomfort with gender role behaviour may arise if tensions exist between gender identity and occupational stereotyping. Conflicts can then occur between the need to maintain masculine identities and feminine associations of the job. Many men expressed their sense of self- fulfilment and the pleasure and satisfaction they gained from their caring role. As one teacher commented:

The best thing is when you've explained something a hundred times to a child that doesn't get it and then finally twigs on and just to see that enjoyment in their eyes that they've achieved something, they've got it and they'll always have it....you can see it in their faces and I think that's where the most enjoyment comes from

For most men, emotional labour was a source of satisfaction and as such they were happy with their chosen careers. However, despite this, some tensions were evident between the feminine nature of the job and dominant conceptions of masculinity.

I often compare myself with my brother who's making million pound deals and he's earning money for his company and I tend to feel when I compare myself with him I tend to feel emasculated really because he's a big City fat cat and would be sat around with a big cigar talking money and I talk about buying more mattresses to enable patients to be more comfortable and it feels kind of soft and unimportant compared to what he's doing (nurse)

Anxiety concerning the (negative) perceptions of others was a common theme:

Seeing myself as a man and as compassionate - but you're always worried about what other people will think, whenever you're like saying I'm a primary school teacher ..because I'm male it's like well what's he up to and why does he want to do that...yes I'm always worried what I tell people and what they think about that...

Several men identified a split in terms of how they presented themselves at work and how they presented themselves outside work e.g. in the social context:

I take almost two roles - when I'm at work I'm one person and when I'm with friends I'm a different person, I think that's how I deal with it...when I'm out with my friends I'm trying to be one of the boys and not let that side (caring) out as much when I'm with them (teacher) 
Changing the job title ('I say I teach music'; 'I always emphasise the sports side'; 'I say I work for a cancer charity') so as to minimise feminine associations were common strategies helping to align gender and occupational identities, particularly in the eyes of others. Therefore, while most men expressed high levels of satisfaction with their career and with the demands of emotional labour associated with the job, role strain in the form of anxiety around and tensions between gender and occupational identity were common.

\section{DISCUSSION}

This paper set out to explore the gendered division of emotional labour, the perception of skills and attributes required for the job and any potential mismatch between gender and occupational identity. Results suggests there exists an emotional division of labour drawn along traditional gender lines with men assigned to or actively choosing 'masculine' specialist functions and more authoritarian and challenging roles. At the same time, in both occupations men were constrained by prescriptive feeling rules (Bolton, 2005) in terms of how they performed emotional labour in that some forms of contact were considered inappropriate and therefore 'out of bounds'. Perceptions of skills revealed levels of similarities and differences when compared with women and with other men. Emotional labour skills performed by men were seen to be different from those performed by women and also to stand out in relation to the (non-caring) skills 'normally' found amongst men. However, evidence suggests some men were keen to align themselves with other men of a higher status than themselves. In this context, nurses recounted their similarity with male doctors and their absorption into the world of male medical practice. Finally, tensions and contradictions existed for men as they attempted to align the feminine nature of the job and their caring role with dominant conceptions of masculinity.

\section{Gender, Presentational and Prescriptive Emotion Management}

These results have several implications. Firstly it supports Bolton's (2005) argument that it is necessary to go beyond original notions of emotional labour which links this work to the capitalist labour process and performed for profit (i.e. pecuniary emotion management) to identify emotion work performed according to professional norms of conduct (prescriptive emotion management) and emotion work as part of normal social interaction in the workplace (presentational emotion management). On this basis, much of the emotional labour undertaken by teachers and nurses can be seen to be in conformance with professional and social feeling rules. Both teachers and nurses follow norms of conduct prescribed by their own profession as well as by social norms of interaction. Teachers for example follow professional norms in terms of how they interact with children in distress (prescriptive 
emotional management) and nurses often 'go the extra mile' to express sympathy and give support to patients (philanthropic/presentational emotion management) despite other pressure on their time.

However, what is of interest here is not so much the relevance of these different types of feeling rules, but their gendered nature. In this respect, as Hall (1993) points out, gender colours what we expect of good service. Women are seen to 'naturally' deliver quality service - it is seen as a natural part of doing gender and one which women are deemed to be capable of by virtue of their sexual difference from men (Taylor and Tyler, 2000). Presentational feeling rules are therefore gendered to the extent that different standards of social engagement in the service encounter are likely to apply. One outcome, as we have seen, may be a greater tendency to perceive men's presentational emotion management as philanthropic i.e. as part of a gift exchange. The high standards of care and the willingness to 'go the extra mile' may be seen as a 'natural' part of femininity and hence undervalued and invisible (Williams, 2003; Taylor and Tyler, 2000) whereas such behaviour may be recognised as philanthropic and given a higher value when performed by men. The tendency for some men to present themselves as 'donor' in such a gift exchange and to claim a higher capacity than women in this respect may be evidence of this effect.

\section{The Significance of Men's Bodies in Emotional Labour}

Results also point to the salience of bodies in organizations and in the construction and implementation of feeling rules. As Connell (2000) points out, bodies matter in that biological difference between men and women play an important part in determining what is seen to be 'masculine' and 'feminine' work. In the context of caring roles, men's bodies are viewed with suspicion and seen as potentially dangerous and disruptive. Accordingly, emotional labour performed by men is constrained by rules which frame how such work should be carried out.

This contrasts with other dominant conceptualisations of men's bodies around physical strength and technical prowess (Bradley, 1989; Reskin and Roos, 1990; Evans, 2004) as well as with underlying assumptions concerning the 'disembodiment' of masculinity (Hassard, Holliday and Willmott, 2000). In the latter case, men can be seen to be divorced from their (largely unproblematic) bodies in some organizational (e.g. management, professional) contexts. Rationality, science and reason, for example, have been assigned as part of the mind to the masculine domain and seen as separate from and a higher order to the body. Men have therefore enjoyed the privilege of invisibility within an unmarked body (Robinson, 2000), the bearers of a "body- transcendent universal personhood" (Butler, 1999. p.14). 
As Hassard et al (2000) points out, while men's bodies in organizations are 'disciplined, disengaged from reproduction, emotionally under control', women's bodies have been 'marked' as Other - a source of disruption and disorder - by virtue of their assumed link with nature. They are accordingly associated with emotionality, sexuality and care (Hassard, et al, 2000), thus contributing to the essentialisation of emotion work as a 'natural' aspect of femininity. In this context, as Robinson (2000) point outs, women have come to embody gender while men have represented unmarked humanity. Against this standard body, other (female) bodies are judged and identified as problematic for organizations. They are consequently 'marked' and made to embody their respective difference from the (male) norm.

As Connell (2000) argues, it is easier for meaning (e.g. around masculinity, femininity) to take hold when the body complies with its social definition. In primary school teaching and nursing the masculine body is very much at odds with its social definition (e.g. as rational, disembodied). On the one hand men may be valued for their bodies (Evans, 2004) and so contribute to a gendered division of labour which assigns men to work that demands physical strength or discipline; on the other hand, men are 'marked' as different from the (female) norm in a context which draw on essential notions of femininity and where women's experiences exist as the 'unmarked' case. When men enter these settings their experiences become marked as men's experiences (they are labelled 'male' teachers and 'male' nurses). Their bodies and their sexuality matter in these contexts. Firstly, their presence in a nonmasculine role calls into question issues around their sexuality and so challenges the heterosexual norm in the work place and secondly their sexuality and masculinity are seen as undesirable, potentially dangerous and disruptive in some of the caring work that they are required to do. Therefore, while in other contexts men may enjoy the privilege of an 'unmarked and a disembodied normativity’ (Haraway, 1991), in a caring role with patients and children, men's bodies are marked as dangerous, disruptive and problematic in ways that resonate with the ways women have been traditionally viewed in work contexts.

\section{Gender, Unity and Difference in Emotional Labour}

As we have seen, men in caring roles are singled out as being something 'other' than nurses or teachers. Difference and unity were themes running though many of the male interviewees accounts of their role. In terms of difference, many men practiced distance from the work performed by women and claimed a difference in skills and attributes in how they performed their role. As in other studies of men in such occupations (e.g. Williams, 1993; Evans, 2002; Heikes, 1991), a gendered division of labour emerged with teachers emphasising their role in physical activities and sport and with nurses often choosing 'masculine' specialisms such as mental health and casualty. In addition, as we have seen, men drew on notions of masculinity (e.g. the ability to mobilise resources or to perform a paternalistic fatherly role) to claim 
special attributes of care and so enhance their value over the essentialised and largely invisible caring work performed by women.

Claims were also made of difference from as well as unity with the male norm. On the one hand, male nurses and teachers declared a differentiation from the majority of other men in terms of their ability to express emotions and to demonstrate care - further enhancing the value and specificity of their skills. On the other hand nurses in particular were keen to claim unity with the 'dominant centre' (Hearn, 1996) of male medical practitioners and exhibited conflict and resentment when they felt outside of that sphere. As Hearn argues, the dominant centres of organizations are rarely secure and can be the site of contradictions and struggles within networks of hierarchies and alliances. Groups can seek to decentre the dominant and promote the visibility of social difference (Robinson, 2000) or, as in this case, can seek inclusion into the norm. Male nurses accordingly draw on fratriarchy to partly enter that domain but are ultimately excluded by patriarchy and their association with the subordinated female role.

\section{Identity Work and Role Strain}

These processes can be understood as part of the identity work men undertake to reduce role strain. Role strain occurs when a tension exists between occupational and gender identity. Evidence from this and other studies (Lupton, 2000; Heikes, 1991; Williams, 1993) attests to the significance of role strain for men in female dominated occupations. As Lupton (2000) points out, men working in female dominated occupations often fear feminization and stigmatization. One response is to reconstruct the job so as to minimize its non-masculine associations i.e. to emphasize the male and downplay the female elements of the job (Williams, 1993). By helping to create a gendered division of emotional labour and thereby carving out a masculine space within the female role, men may be able to alleviate 'role strain' as they encounter tensions or contradictions between norms of masculinity and the demands of the job. At the same time, men may resist the identity and embodiment of Other within their caring role by drawing lines of division based on difference as well as creating spaces of unity within and around the work context.

These demarcations and alignments not only help to enhance the specificity and value of those caring skills when practiced by men but can also be seen to constitute 'gender work' undertaken as men construct and reconstruct a masculine identity in their work role (Connell, 2000). Post-structuralists place emphasis on the tensions and contradictions inherent in identity construction and maintenance. In this context, rather than stable categories, masculinity and femininity are seen as ideologically and discursively produced and hence as contingent, fluid and uncertain (Whitehead, 2001; Kerfoot and Knights, 1998; Collinson and 
Hearn, 1994). This places emphasis on the social and organizational contingency of subjectivity. Identity is accordingly an ongoing project (Sveningsson \& Alvesson, 2003), which is mobilized, negotiated and renegotiated in day to day activities as people try to make sense of their uncertain or ambiguous work contexts, the demands of role expectations and their own self doubt.

One dominant discourse is hegemonic masculinity which, as Connell (2000) points out, men internalize and attempt to act out in day to day practices. In caring roles, however, men's relationship to this dominant ideal is made precarious by associations with femininity, so exacerbating the anxiety and insecurity (Kaufman, 1994) that accompanies negotiations around a masculine identity. This can be seen in the tension and conflict around the dominant centre of organizations as nurses in particular attempt to align themselves with higher status males as well as in the ambiguities inherent in the lines of demarcation drawn between male carers and women.

\section{CONCLUSION}

This paper has highlighted the gendered nature of emotional labour by exploring the attitudes and experiences of 'men who care'. Drawing on Bolton's typology of emotional labour, it has highlighted the ways in which these feeling rules may be considered gendered and the implications of this gendering for men and women in caring roles. While the gendered nature of emotional labour has been implicit in much of the work in the area, more explicit theorising is required in order to unravel some of the gendered processes involved and to disconnect emotional labour from assumptions about 'essential' masculinity and femininity. Such work is important if sex stereotypic occupation boundaries are to be challenged and if we are to successfully recruit more men into these roles. 


\section{REFERENCES}

Adkins, L. (2001) Cultural Feminisation: money sex and power for women. Signs. 26 (3): 669-95

Alvesson, M. (1998) 'Gender Relations and Identity at Work: A Case Study of Masculinities and Femininities in an Advertising Agency', Human Relations, 51,8, 113-126

Bolton, S. and Boyd, C. (2003) Trolley Dolly or Skilled Emotion Manager? Moving on from Hochschild's Managed Heart, Work Employment and Society, Vol 17 (2): 289 - 308

Bolton, S. (2005) Emotion Management in the Workplace, Palgrave.

Bradley, H. (1993) 'Across the Great Divide' in C. Williams (ed) Doing Women’s Work: Men in Non-Traditional Occupations, London: Sage

Butler, J. (1994). Gender as performance: an interview with Judith Butler, Radical Philosophy, 67: 32-39

Butler, J. (1999) Gender trouble: Feminism and the subversion of identity, London: Routledge

Collinson, D. \& Hearn, J. (1994) Naming men as men: Implications for work, organization and management, Gender Work and Organization, 1,1, 2-22

Connell, R. (2000) 'The Men and the Boys', Cambridge: Polity Press

Corbin, J. and Strauss, A. (1990) 'Grounded Theory Research: Procedures, Canons and Evaluative Criteria', Qualitative Sociology 13,1: 3-21 
Evans, J. (2004) Bodies Matter: Men, Masculinity and the gendered Division of Labour in Nursing, Journal of Occupational Science, vol 11 (1): 14-22

Floge, L. and Merrill, D. (1986) 'Tokenism Reconsidered: Male Nurses and Female Physicians in a Hospital Setting', Social Forces, 64,4, 925-947

Gherardi, S. (1995) Gender, Symbolism and Organizational Cultures, London: Sage

Guerrier, Y. and Adib, A. (2004) Gendered Identities in the Work of Overseas Reps, Gender Work and Organization, vol 11 (3): $334-350$

Hall, E. (1993) Smiling, Deferring and Flirting: Doing Gender by Giving Good Service, Work and Occupations, Vol 20 (4): 452 - 471

Haraway, D. Simians, cyborgs and women: The reinvention of nature, New York and London: Routledge, 1991

Hassard, J., Holliday, R. \& Willmott, H. (2000) Body and Organization, London: Sage

Hearn, J. (1996). Deconstructing the Dominant: Making the One(s) the Other(s), Organization vol 3 (4): 611-626

Heikes, E. (1991) When men are the minority: The case of men in nursing, The Sociological Quarterly, 32 (3): 389-401

Hatcher, C. (2003) Refashioning the Passionate Manager: gender at Work, Gender Work and Organziation, Vol 10 (4):391-412

Hochschild, A. (1983) The Managed Heart. Berkeley: University of California

James, N. (1989) Emotional Labour: Skill and work in the social regulation of feeling, Sociological Review, 37: 15-42

Lupton, B. (2000) 'Maintaining Masculinity: Men who do Women’s Work', British Journal of Management, 11, S33-48 
Kerfoot, D. \& Knights, D. Managing masculinity in contemporary organizational life: A managerial project, Organization, 1998, 5, 1, 7-26

Morgan, D. (1992) 'Discovering Men', London: Routledge

Morris, A. and Feldman,. D. (1996) The Dimensions, Antecedents and Consequences of Emotional Labour, Academy of Management Review, vol 21 (4): 986-1010

Mulholland, K. (2002) Gender, Emotional Labour and Teamworking in a Call Centre, Personnel Review, Vol 31 (3): 283 - 303

Mumby, D. and Putnam, L. 1992. The Politics of Emotion: A Feminist Reading of Bounded Rationality, Academy of Management Review, Vol 17 (3): 465-486

Murray, S. (1996) We all Love Charles: Men in Childcare and the Social Construction of Gender, Gender and Society, vol 10 (4): 368 - 385

Reskin, B. and Roos, P. (Eds) Job queues, gender queues. Philadelphia: Temple University Press

Robinson, S. (2000) Marked men: White masculinity in crisis, Columbia University Press

Ross-Smith, A. and Kornberger, M. (2004). Gendered rationality: A genealogical exploration of the philosophical and sociological conceptions of rationality, masculinity and organization. Gender Work and Organization, 11 (3): 280-305

Sass, J. (2000) Emotional labour as cultural performance: The communication of care giving in a nonprofit nursing home, Western Journal of Communications, Vol 64 (3): 330-358

Smith, P. The Emotional Labour of Nursing, Basingstoke, England: McMillan

Sturdy, A. (1998) Customer Care n a Consumer Society: Smiling and Sometimes Meaning it? Organization, Vol 5 (1): 27-53 
Sturdy, A. (2002) Knowing the Unknowable: A discussion of methodological and Theoretical Issues in Emotion Research in Organization Studies, Organization, Vol 10 (1): 81 - 105

Sveningsson, S. \& Alvesson, M. (2003). Managing managerial identities: Organizational fragmentation, discourse and identity struggle. Human Relations, 56: 1163-1193

Williams, C. (2003) Sky Service: The Demands of Emotional Labour in the Airline Industry, gender Work and Organization, Vol 10 (5): 513 - 550

Williams, C. (1993) (ed) 'Doing Women’s Work: Men in Non-Traditional Occupations' London: Sage

Wouters, C. (1989) The Sociology of Emotion and Flight Attendants: Hochschild's Managed Heart, Culture and Society, Vol 6: 95 - 123

Wharton, A. (1993) The Affective Consequences of Service Work: Managing Emotions on the Job, Work and Occupations, Vol 20 (2): 205 - 232

Whitehead, S. (2001) Woman as manager: A seductive ontology. Gender Work and Organization, 2001, 8, 1, 84-107

Williams, C. Doing women’s work, London: Sage, 1993 